\title{
Coastal Ground Water Flow and Management: A State-of-the-Art Review
}

\author{
Ghritartha Goswami, Sudip Basack, Nikos Mastorakis, Abhishek Saikia, Baby Nilo and Nasir Ahmed
}

\begin{abstract}
Seawater intrusion has led to salinization of fresh groundwater reserves in coastal areas worldwide and has forced the closure of water supply wells. There is a paucity of well-documented studies that report on the reversal of SWI after the closure of a well field. Saline water from a storm surge can flow down storm-damaged submerged water supply wells and contaminate boreholes and surrounding aquifers. Water is an invaluable commodity in nature and can be a limiting resource to man and other living beings. Water quality is influenced by both natural and anthropogenic intervention where the former includes local climate, geology etc., and the latter covers the construction of dams and embankments, irrigation practices, indiscriminate disposal of industrial effluents etc. Therefore, it is highly desirable to properly manage groundwater resources for drinking-water supply by controlling saltwater intrusion. A cost effective method Abstraction, Desalinization and Recharge was found to be efficient.
\end{abstract}

Keywords - Salt water Intrusion. Salinization, Water quality.

\section{INTRODUCTION}

Tit HE coastal groundwater flow and management ludes

flow of sea water into the fresh aquifer zone as well as the discharge of fresh groundwater from coastal aquifer back into the sea. The former is termed as saline water or saltwater intrusion (SWI), while the latter is called the submarine groundwater discharge (SGD). Many factors have been identified as the reasons for SWI, including significantly high groundwater withdrawal through pumping from coastal aquifers exceeding the rate of recharge. Secondly, it has been identified that saline water intrusion can also result from the density difference between the more dense saline water in the

This work is based on the theoretical investigation carried out by Abhishek Saikia, Baby Nilo, and Nasir Ahmed the fourth fifth and sixth author herein, as a part of their academic research curriculum at Scholar's Institute of Technology and Management, Guwahati, Assam, INDIA.

Ghritartha Goswami, is with the Scholar's Institute of Technology and Management, Assam, INDIA (e-mail: goswami.ghritartha@gmail.com).

Sudip Basack is Principal of Elitte College of Engineering, Sodepur, Kolkata, INDIA (corresponding author phone: +91-8617715761; e-mail: basackdrs@hotmail.com).

Nikos Mastorakis is with the technical University of Sofia, Department of Engineering, Sofia, BULGERIA. (e-mail: mastor@tu-sofia.bg)

Abhishek Saikia, is with Scholar's Institute of Technology and Management, Assam, INDIA. (e-mail: abhisheksaikia011@gmail.com).

Baby Nilo, is with Scholar's Institute of Technology and Management, Assam, INDIA. (e-mail: babyniloo1997@gmail.com).

Nasir Ahmed, is with Scholar's Institute of Technology and Management, Assam, INDIA. (e-mail: nasir57578@gmail.com). sea and the less dense fresh water in the aquifer During the

study, it was observed that the researchers approached different ways towards the analysis and control of SWI and SGD, including theoretical modelling (numerical or analytical), laboratory-based studies and field investigations. Few researchers also provided useful design recommendations. In this paper, a brief overview on the past state-of-the-art contributions has been briefly described.

In coastal regions, the complex hydrogeological system makes scientific groundwater management in coastal region very necessary. Even for unconfined aquifer, a constant drawdown in ground water underneath sea level increases the risk of saline water intrusion. Although different methodologies are available to control SWI, still uncontrolled ground water extraction and development are the two major factors which increases the saline water intrusion by the reversing freshwater gradient.

\section{REVIEW OF LITERATURE}

\section{A. Theoretical Analysis}

Calvache and Bosch [1] proposed a mathematical model of ground water flow in three aquifers on the southern coast of Spain, namely Rio Verde, Rio Velez and Castell de Ferro. In the step Calvache and Bosch [1] used a flow model to demonstrate the physical and hydraulic parameters of the aquifer. Calvache and Bosch [1] in his modeling took the help of two models, MODFLOW model and the BADON 2 model. The MODFLOW model used the method of finite differences to solve equations of ground water flow and the BADON 2 resolve the flow equation for salt/fresh water in finite elements. In the next step Calvache and Bosch [1] had to simulate the fresh water contact as a single fluid. In this step Calvache and Bosch [1] had to use the data obtained in MODLOW. For this step to proceed MOCDENSE was used which was nothing but a two constituent solute transport model for groundwater of different density. After the completion of the whole process Calvache and Bosch [1] stated that the three aquifers studied were affected by salt water intrusion, because of over exploitation of their resources. The inhabitants must keep in mind that the extraction must be less than the recharge. Calvache and Bosch [1] also concluded that the contamination of each of the aquifers operates differently. After keeping in mind the dynamics of extraction and peculiarities affecting intrusion, 
Calvache and Bosch [1] proposed various counteractive measures in each aquifer. Therefore, any attempt of rectifying correcting an aquifer affected by salt water intrusion, we must have proper knowledge of the whole area because the best solution of one system is not necessarily applicable to other aquifers.

Khublaryan et al. [2] in this paper reviewed the hydrological, hydro physical and hydro chemical features of the interaction between marine waters and groundwater in the surrounding land territory. He manifested the general process of interaction between surface and subsurface waters. Khublaryan et al. [2] reviewed the intrusion of saltwater into aquifer in addition to submarine groundwater discharge. This paper involves the mathematical modelling of seawater intrusion in which it is divided in two group, which depends on whether a sharp interface is assumed to exist between fresh and saltwater or waters are assumed to mix. Khublaryan et al. [2] said that a thorough examination is needed to see the effects of saltwater intrusion in coastal areas as the water requirement in the territories which are connected to the sea increases. These models show the extent of contamination in the fresh groundwater by saltwater. This can be done by calculating the penetration depth of saline water into fresh ground water aquifers. There are two models through which this calculation is carried out i.e. in the regime of adjective diffusion (dispersion). This helps in designing the layout of water intake in coastal regions to ensure that the quality of water is good and free from saltwater.

Kacimov et al. [3] studied experimentally, analytically and numerically the sea water intrusion on the coastal aquifer on the Batinah area of Oman. He state that the water table elevation which is due to saline water intrusion, capillary fringe and moisture distribution were observed and measured at a pilot site Al. Hail, Oman. He conducted the laboratory measurement of hydraulic conductivity, capillary rise in repacked column in laboratory. HYDRUS 2D were use in modelling the evaporation from shallow horizontal water to a dry soil. In his model Kacimov et al. [3] studied the area consists of six surface catchment (total area of 5400 square $\mathrm{km}$ ) and each strip has dimensioned around 40-50 km. He use Dupuit forchheimer model for catchment, first DF model describe analytically the flow of fresh ground water from land of high elevation and flow of saline water that intruded from the sea which is generated by distributed losses from water table. The losses simulate the consumptive pumping from the fresh ground water, shallow horizontal saline water evaporation and artificial pumping out intruded sea water. Kacimov et al. [3] stated that the balanced interface between fresh water and saline water hangs with its toe on impermeable underlying bed and three points where three free layers are separating the fresh, saline water and vadose zone into aquifer. In his study Kacimov et al. [3] used SUTRA modelling for saturated-unsaturated, variable-density flow with solute transport. He stated that sutra model is the upgrade of sutra computer code from 1984. Sutra model is a numerical simulation which is done to examine the possibilities of restoration of the groundwater quality near the area of coast of the sea. Kacimov et al. [3] developed the interface model for constant water table losses of fresh and intruded saline water.
They established the idea of intruded related zones of aquifer i.e. from zone 0 to zone 5 and each zone has characteristics, although there is no hydraulic contact between groundwater and beach, sea water can penetrate deep intersect.

Naidu et al. [4] carried out in the central Godavari delta which is located along the Bay of Bengal Coast, Andhra Pradesh and is drained by Pikaleru, Kunavaram and Visalatippa drains. In this paper Naidu et al. [4] has done an integrated approach to investigate saline water intrusion as there is no groundwater pumping for domestic purpose or agriculture due to the salinity in the groundwater. The main survey they have done is Electrical Resistivity Tomography (ERT) survey in several locations to find out the exact or precise location of saline water aquifer zones. They have collected samples from many boreholes and analyzed electrode for ions to identify salinity origin. Naidu et al. [4]found that the result from ERT surveys shows low resistivity values in the areas near the Central Godavari coast which is caused due to the thick marine clays from ground surface and high resistivity values in the areas away from the coast. The high resistivity is due to the presence of coarse sand. Naidu et al. [4] further observed that the salinity is caused due to marine paleosalinity, dilution of marine clays and dissolution of evaporation which is rich in sodium.

Javadi et al. [5] proposed the method ADR-TW (abstraction desalination recharge of treated waste water) which is based on a combination of abstraction of saline water near shoreline, desalination of abstracted water for domestic consumption and to maintain sustainability of the aquifer it is recharged by deep injection of treated wastewater to maintain the hydraulic head. In is method he investigated about water quality, capital and cost of maintenance along with other scenario of ground water management. This method is the extension of ADR (abstraction desalination recharge) method proposed by Elhamid and Javadi in 2011 [28] in which desalinated water is use to recharge the hydraulic loss in aquifer. The main objective of Javadi et al. [5] study focuses on the developing and application of simulation-optimization technique which is use for assessing different management method to control the saline water intrusion. Javadi et al. [5] examined three different management scenario of saline water intrusion to check the efficiency of ADR-TW method and compared it with ADR method and other management scenarios. In his method Javadi et al. [5] considered three different management scenarios to control the saline water intrusion. Those three scenarios involved are (1) use of recharge well (2) use of abstraction well (3) combination of abstract and deep recharge. Different schemes were use to investigate the efficiency of these scenarios. After the investigation of efficiency for recharge scenario it is found that recharge by treated wastewater with $1300 \mathrm{mg} / \mathrm{l}$ solute concentration has a better efficiency then the desalinated water with lower TDS (total dissolved solid) which is due to lower market value of treated wastewater as compared to the desalinated water. For abstraction scenario he stated that the cost saline water extraction and its disposal to the sea is less than that of recharge scenario and mass of concentration in aquifer has no significant reduction as compared to recharge scenario. He has given the dimension for optimal location and depth for the 
pumping well which is $176-180$ and 90 meters. Third scenario is combination of both and after third scenario it's shown that ADR may be able to manage the control of saline water intrusion but ADR-TW is more effective method in control management of saline water intrusion.

Momejian et al. [6] has done study to see if the groundwater vulnerability models can be used to find out the quality of water and evaluate the seawater intrusion. The models are developed to provide information on groundwater conditions and medium containing the groundwater. In this paper, two commonly used GVA (groundwater vulnerability Assessment) models which is coupled with GIS (geographic information system) based models namely DRASTIC (Depth of water(D), Recharge(R), Aquifer Media(A),Soil media(S), Topography(T), Impact of Vadose zone (I), Conductivity(C)) and EPIK ( Epikarst(E), Protective Cover(P), Infiltration(I), Karst network development $(\mathrm{K})$ ). These two models are used in assessing seawater intrusion in the region of Eastern Mediterranean coastline. Momejian et al. [6] compared Total Dissolved Solids (TDS) in groundwater samples with mapped vulnerability prediction obtained from DRASTIC and EPIK in three areas Beirut, Jal el Dib, Tripoli. During field assessment they got high levels of groundwater salinity which depends on the urbanization whereas a GIS model has a limited ability in finding saltwater intrusion dynamics. Thos models works poorly when anthropogenic activities induced from saltwater intrusion is done. Momejian et al. [6] find out that DRASTIC and EPIK have limited abilities in defining quality condition in groundwater.

Stein et al. [7] studied the effect of pumping saline groundwater from phreatic coastal aquifers on fresh groundwater for desalination on the fresh-saline water interface. The problem of seawater desalination has become very essential for freshwater supply in arid and semi-arid regions. For this purpose, they have constructed 3-D phreatic coastal aquifer model by using FEELOW software. This model can solved the coupled variable density groundwater flow and solute transport equation. Stein et al. [7] compared the result from model to those of field-scale pumping test. The result he found indicates that the aquifers are freshened by the pumping Saline groundwater from a coastal aquifer and it rehabilitates other parts that were salinized by seawater intrusion. This effect is increasing by increased pumping test. Stein et al. [7] observed that the simultaneously pumping fresh groundwater and saline groundwater from below the fresh saline-water interface freshens less whereas the salinity of aquifer is more stable. Over the course of pumping salinity decrease, due to the high-quality source feed water for desalination. He said to overcome this saltwater intrusion issues by reversing the process in overexploited aquifers.

\section{B. Laboratory Experimentations}

Kefford [8] has monitored or study the effect of saline water disposal on the aquatic macro invertebrates and water quality which was conducted in the Barwon river, south west Victoria, Australia. Later he runs the toxicity tests on water. In his method Kefford [8] first study the area of Barwon River and stated that the main cause of Salinity in Barwon river is the Lough Calvert Drainage Scheme which was constructed in early $1950 \mathrm{~s}$, this scheme diverts the water from saline lake into Birregurra creek which is a ephemeral stream that joins the Barwon river since it is a lowland river. After the study of area he collected the sample of macro invertebrates from three sites at the Barwon River immediately upstream and downstream of Birregura creek and at Birregurra creek. Later he collected the water quality data of Barwon-Birregura confluence and analyzed the data. After the sampling, the sample is used to validate the BACI (Before-After ControlImpact) design. Kefford [8] also investigated the toxicity of river water to check whether electrical was only toxic aspect of saline lake's water or not. He prepared a solution of same electric conductivity and compared the both, after comparison he found out that toxicity is more in saline lake's water as compared to prepared solution which effects the macro invertebrate fauna and result of the toxicity clearly shows that electric conductivity is not only the toxic aspect of saline lake's water.

Rahman et al. [9] did some environmental assessment on water quality deterioration caused by the decreased Ganges outflow and saline water intrusion in south western Bangladesh. The study was done during a dry period at the Khulna and Mongla port areas in south-western Bangladesh. The main reason for the drastic fall of the Ganges low flow condition in the Bangladesh territory during dry period is due to the large scale water withdrawal in India after commissioning the Farakka Barrage. The average lowest discharge in the Ganges has come to $552 \mathrm{~m}^{3} / \mathrm{sec}$ which is around $73 \%$ less than the pre Farakka times. This was the main reason for deterioration of both the surface water and ground water quality. Rahman et al. [9] studied and found that Bangladesh is largely dependent on the surface water and ground water and around $90 \%$ of the drinking water comes from the aquifer. Therefore if there is any contamination in this main source of water then this will lead to a very serious disaster in the socio economic environment of Bangladesh. In their study they found a new problem that is the arsenic problem in the ground water which is a matter of concern in the whole nation. Rahman et al. [9] concluded the investigation by stating that as compared to the average peak flow before 1975, the average peak discharge has increased by $12 \%$. The major problem of salinity in Bangladesh is largely influenced by the Bay of Bengal which was caused by the reduction in the Ganges water flow, which lowers the river water level and ultimately paves the way for saline water intrusion into the fresh water zone of the study area. Rahman et al. [9] also added that no efforts has yet been made to determine ground water removal as a cause of seawater intrusion in the fresh water aquifer because groundwater development began only during the last decade and removal is still only small scale.

Choudhury et al. [10] investigated the contamination of water in subsurface saline water in the alluvial coastal belt of Digha. The paper consist of geophysical surveys in different subsurface levels are electrical resistivity and shallow seismic refraction methods. From the geophysical survey conducted by Choudhury et al. [10] it is concluded that the depth of nearsurface saline zone is less inland from the sea. In Digha, the 
subsurface layer have large clay layer which resist the saline water intrusion at depth of about $60 \mathrm{~m}$ below which an aquifer zone has distinguished. Choudhury et al. [10] have founded some areas that are already saline or which are exposed to the possibility of saline water intrusion. They also founded areas where exploitation of groundwater which have comparatively safe zone for saline intrusion has been precisely noted. In this paper, Choudhury et al. [10] observed that geographical methods are highly useful and very much accurate in investing saline water intrusion in alluvial terrain with the presence of clay layers.

Vives et al. [11] conducted the study in the Salliquello country located in the western part of Buenos Aires Province, Argentina. The area was found to have the most negligible surface water resources, and ground water is the only fresh water source for human, animal and irrigation requirements. Salliquello has the most important fresh water reserves in the country. Vives et al. [11] has put efforts in protecting the fresh water sources of the country particularly the lens that provided the capital. He added that the groundwater resources should be developed rationally. From there efforts they listed out some of the measures that has to be taken in order to improve the aquifers. It was found that the saline front rises rapidly when water is extracted from the silt. By this it was assumed that in the long term the aquifer will produce up-coning in a very similar way whether it is pumped from the sand or from the silt. Therefore a strategically used water-supply wells should control the saline interface position. They suggested for the construction of a protection perimeter that encompasses the water supply wells. The materials that make up the upper portion of the aquifer was found to be sandy which is very permeable therefore it is necessary to assure that the distance from wells to any potential pollutant source location is adequate. Vives et al. [11] also added that the main source of water supply should be present outside the main city keeping in mind the present contamination of the groundwater. It is also suggested that water should be pumped only in the critical supply periods. They also found that the water and sewer net losses show a great result of contamination, therefore investigations, repairs and maintenance of these services are required to reduce this risk. They also proposed for a new location of waste disposals Recycling part of the residuals, and storing the remainder in the form of a secure landfill would be a desirable solution. Therefore proper awareness must be made within the inhabitants of the area regarding the issue. Finally Vives et al. [11] suggested some guidelines for the management and protection of fresh water reserves like the deactivation of supply wells in the urban domain. They suggested for the proper monitoring of the saline interface position and establishment of protective perimeter for water supply wells.

Carlson et al. [12] conducted their study in the shoreline community of Lake Pontchartrain, St. Tammany Parish, in southeastern Louisiana, United States, which was impacted by two hurricane storm surges and had neither been rehabilitated nor chlorinated. They researched that the saline water that was driven by storm surges can flow down to storm damaged water supply wells and contaminate the boreholes, which results in heavy impact to the surrounding coastal aquifers. On august 29,2005, hurricane Katrina and on September 24, 2005, hurricane Rita made landfall along the south eastern coast of Louisiana, As it moved northward toward Mississippi, it forced a major surge of saline Gulf of Mexico water into Lake Pontchartrain. From the study of the above two surges, the wells pressure tank and plumbing above the wells riser pipe were ripped away and was left an open riser pipe which provided an easy path for the saline water to flow in the wells casing and off course the aquifer. Various tests were conducted including the Purging test. Purging test was conducted until the chemical parameters reached stable values. TDS values were determined by gravimetric method using an approximately $100-\mathrm{mL}$ sample. All weights were measured to the nearest 0.001 of a gram. All the laboratory tests were conducted during the fall of 2005 in accordance with standard testing methods by several laboratories. The samples collected in 2006 were tested in the LGS wet chemistry lab and Wetland Biogeochemistry Institute lab at Louisiana State University (LSU). After the experiment Carlson et al. [12] came to a conclusion that impact of Hurricanes Katrina and Rita was still evident after 9 months. A purging test was conducted in June 2006 and lasted approximately 4 hour with a pumping rate that was 12065 $\mathrm{m}^{3} /$ day, during which water samples were periodically collected for later chemical analysis. Carlson et al. [12] concluded by stating that the values of TDS concentrations were nearly constant during the purging test and saline water from storm surges can flow down submerged, damaged boreholes, contaminating wells and surrounding coastal aquifers.

Loaiciga et al. [13] carried out in the city of Monterey, California (USA), where they gave a mathematical formulation via numerical simulation for the sea level rise and seawater intrusion in the 21 st century. The paper illustrated that the sea level rise is due to increasing global mean surface temperature. Loaiciga et al. [13] presented models which are carried out with state art numerical model to find out the effect of salinity on groundwater density. For this mathematical formulation three key scenarios named Herein Scenarios I (post-2006 groundwater extraction and $1 \mathrm{~m}$ sea-level rise), III (baseline groundwater extraction and $1 \mathrm{~m}$ sea-level rise), V (post-2006 groundwater extraction and baseline sea level) are done. The results predicts that an expanded zone of sea water intrusion under scenario $\mathrm{I}$ is closer to coastal protection compared to sea water advance under scenario V. Loaiciga et al. [13] concluded from his numerical simulation that the main reason for sea water intrusion is groundwater extraction in the sea side area of sub basin. 


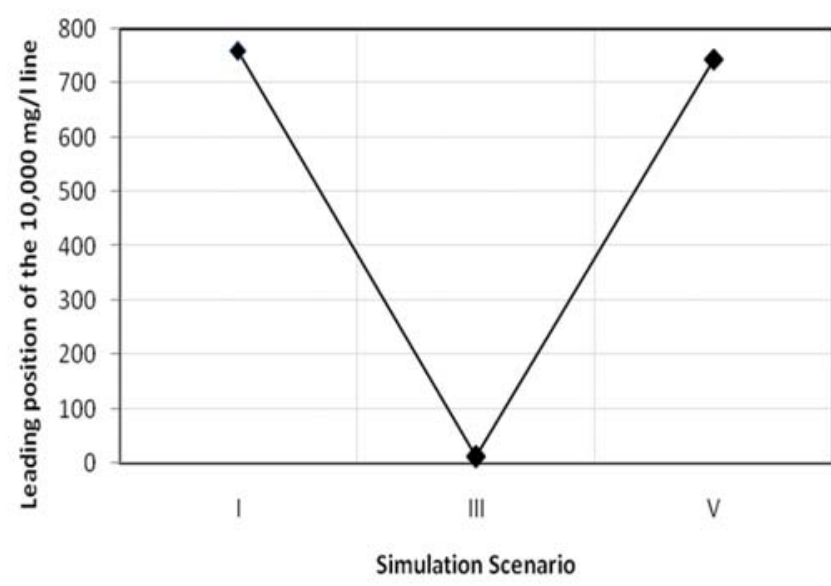

Fig. 1: Position of the $10,000 \mathrm{mg} / \mathrm{L}$ iso-salinity line (modified after Loaiciga et al. [13])

Singaraja et al. [14] studied on the status of salt intrusion in the coastal hard rock aquifer of Tuticorin district located in south east coast of Tamil Nadu, India. He state that the study area covers about 4,590.54 square kilometers. District is the origin of few stream which is ephemeral in nature so runoff is generated only in the heavy rainfall period and after flowing 10-20 kilometer, it directly confluence with the sea. In their study Singaraja et al. [14] found that the main constituent of an aquifer are (1) unconsolidated and semi consolidated formation (2) weathered and fractured crystalline rocks. Singaraja et al. [14] carried out the field investigation on July 2013 to collected 135 groundwater samples from the hand pumps in the entire district of Toothukudi. After collecting the samples he measured the Alkalinity and various physical parameters on the field such as $\mathrm{pH}$, temperature, electrical conductivity(EC) and total dissolved solid (TDS). In their investigation he used flame photometer to measure the sodium $(\mathrm{Na}+)$ and potassium $(\mathrm{k}+)$ and for determination of concentration of calcium, magnesium, chlorine and bicarbonate he use volumetric titration method (APHA 1992). After the investigation Singaraja et al. [14] concluded that the groundwater samples that is collected from the study area are alkaline in nature has a $\mathrm{pH}$ ranging from 6.30 to 9.20 and average of which is 7.57 .

Han et al. [15] researched that Sea water intrusion (SWI) has dipped huge fresh water reserves into the trap of salinization in the coastal carbonate aquifer in Northeast China where large scale extraction has ceased since 2001 after sainization of the main well field. Han et al. [15] studied the physical flow and concomitant hydro geochemical processes by analyzing water level and geochemical data, including major ion chemistry and stable water isotope data. He selected the Dalian region of China where ground water salinization occurred as early as 1964 . Dalian is located in the southern tip of Liaodong Peninsula, and is one of the most important industrial regions of China. Many more researches were conducted in this area before which focused on identifying extend of salinization near the Daweijia well, field which formed one of the largest ground water sources for Dalian city. Han et al. [15] said that salinization is not only caused by Saline Water Intrusion (SWI) but also by human activities (eg, agricultural irrigation, fish farming) and drought. The main uniqueness about the Han et al. [15] study was that, they were the first to comprehensively characterize the ground water flow system in the coastal carbonate aquifers in northeast china. The study in Dalian city got more interesting because there the salinization became so severe that the Daweijia well field was forced to shut down in 2001. Based on existing monitoring network by the Chinese Geology Survey, ground water was collected from 31 ground water wells ranging from 8.4 to $128 \mathrm{~m}$ depth during three periods from June 2008 to August 2010 along a $9.6 \mathrm{~km}$ transect. Nineteen of the sampled well are screened in the carbonate aquifer and 12 wells in the quaternary aquifer. Two sea water sample and one rainfall sample was also collected. Water table depth below land surface was measured before pumping. $\mathrm{PH}$, temperature, dissolved oxygen (DO) and electrical conductivity (EC) was measured using portable meter. Water samples were taken after constant values of conductivity and redox potential of the pumped water has been reached. Han et al. [15] finally studied the results and found that seasonal water table and salinity fluctuations, as well as changes of hydrogen values of ground water between the wet and dry season suggests local meteoric recharge with pronounced seasonal regime. DHan et al. [15] concluded that massive expansion of fish farming in sea water ponds in the coastal zones poses a new risk of salinization. Some processes like the cation exchange, carbonate dissolution and fertilizer application are the dominant processes that modify the ground water composition that was investigated quantitatively using hydro chemical models.

Ngo et al. [16] observed and studied the sustainability risks of Ho Chi Minh City, which is one of the largest cities in the southern east region of Vietnam. It has an area of 2,095 $\mathrm{km}^{2}$ with more than 7.5 billion inhabitants. Study was conducted specifically in that city because that city was the economic centre of the whole country. Two large rivers, the Saigon and the Dongnai, flow through the Ho Chi Minh area from the northeast to the Can Gio Sea in the south. In their study, Ngo et al. [16] collected a total of 33 hydro geochemical data from the aquifer from The National Monitoring Database for the Ho Chi Minh area, collected by the Division for Water Resources Planning and Investigation for the South of Vietnam. The results of Ngo et al. [16] included information's regarding the ground water quality, stable isotopes signature of groundwater, long term changes in ground water, groundwater sustainability, he also included that aquifers of Ho Chi Minh City had both fresh and saline water bodies. They also added that salinization of groundwater in the Upper Pliocene aquifer is largely a result of the mixing of freshwater with seawater. This was found by the $\mathrm{Br}: \mathrm{Cl}$ ratio and stable isotope measurements. In their study it was observed that there was an uninterrupted decline of water level in the long term monitoring wells. This indicated that there is a water level decline that resulted not from the effects of climate but from groundwater exploitation, Ngo et al. [16] .

Liu et al. [17] in this paper studies the problem of saline water intrusion in intrusion in southern Laizhou Bay by using hydrochemical and stable isotopic methods and the 
Hydrochemical Facies Evolution Diagram (HFE-diagram). Liu et al. [17] founded that the major factor for groundwater distribution is the structure of the sedimentation layer. In their study they observed and explained that the hydrochemical data shows saline water formed through dissolution of evaporates in the Holocene groundwater and Late Pleistocene groundwater. The isotopic data shows that the main recharge of saline water is the mixture of meteoric water and lateral recharge from river. Liu et al. [17] concluded their research by saying that there have been significant increase in saltwater intrusion by the decreasing and unbalanced precipitation and intensive river cut-off which ultimately decrease groundwater recharge, if brine exploitation is stopped, the salt will be dissolved by fresh-water which can be done by prolonged replenishment, migration, filtration and capping condition. This will decrease the amount of recharge and influence the quality of new brine resources.

$\mathrm{Xu}$ et al. [18] proposes an analytical model to show saltwater intrusion in the estuaries with several freshwater sources. As the saltwater have negative effect on estuarine eco-environment. The effect of river discharge is different in multiple source estuaries to those in single source estuaries on the salinity distribution. Here a model is derived from advection dispersion equation for salinity considering the effect of hydrodynamics variation along the estuary. Xu et al. [18] taken a human estuary with two major sources of freshwater and done eight surveys over complete spring-neap tidal cycle. This survey shows the result that the model can be used to determine the salinity distribution in multiple freshwater source estuaries. Xu et al. [18] has also done field in comparison to this result which shows salt intrusion process exhibits segmentation although inherent characteristic of estuary remains the same. In this paper, Xu et al. [18] showed an efficient and effective model to predict the salt water intrusion length of the human estuary which can be used in practical application.

\section{Field-Based Studies}

Han-xue et al. [19] observed that saline water intrusion was found in Israel, Thailand, Spain and the Fuji area of Japan. In china a large scale sea water intrusion was observed in the last twenty years which has now become a very serious issue as the extend of intrusion area has reached to 400 to $500 \mathrm{~km}^{2}$. They also marked that seawater intrusion led to the salinization of the fresh water field and the erotion of pumping equipments. Han-xue et al. [19] conducted their study in the Laizhou area which is in the north coast of Shandong Peninsula, Shandong Province, China and had three groups of rock sediments. They observed that before 80's the saline water area was controlled by the natural salt water deposits in the marine sediment aquifer and by sea tide, but after the dynamic balance between fresh water and saline water was damaged by the increasing ground water exploitation afterwards, the freshwater/ground water interface moved inland $10 \mathrm{~km}$ a year in average from 1980 to 1990 so that the increased area of intrusion is now about $300 \mathrm{~km}^{2}$. Han-xue et al. [19] finally concluded that saline water intrusion in the Laizhou area is mainly due to three factors- tide, excessive extraction of groundwater, and original saline water leakage. They suggested the construction of underground dams across estuaries to prevent sea water intrusion and preserve the fresh ground water from upstream.

Yukun et al. [20] analyzed the characteristics, pattern, hydrodynamic and hydro-chemical features, and the movement pattern of the salt water fresh water interface of the sea water intrusion and the salt water intrusion, which occur in the coastal areas of Laizhou Bay in Shandong Province. In their study area Yukun et al. [20] figured it out that sea water intrusion occurred mainly along the coast of Laizhou Bay, from Zhenzhu, Laizhou to the right side of Huangshuihe River in Longkou. During their study in the area, Yukun et al. [20] listed out some characteristics of the salt water intrusion. Firstly they observed that sea water intrusion is spot intrusion which was observed at some specific, isolated spots, each quite small in area (less than $0.5 \mathrm{~km} 2$ ). Then it spread out gradually and covered a larger area by linking some isolated spots together. Eventually, it covered the entire coast and developed into "planar intrusion". They also added that salt water intrusion is by many factors such as groundwater discharge and pumping mode, precipitation and so on. It is not absolutely that "once occurred, expand rapidly". Yukun et al. [20] concluded their study by saying that sea water intrusion is a phenomenon caused by excessive pumping of fresh water. In the process of salt water formation and intrusion, there exist complex dissolution, deposition, cation exchange and absorption.

Al-Garni and El-Kaliouby [21] selected the Wadi Thuwal area which is in the west part of Saudi Arabia close from the red sea. Their main objective of this study was to locate the extent of seawater intrusion and to map the shallow layer aquifer in the region where water accumulates from the rain or water flooding. Al-Garni and El-Kaliouby [21] was aware of the electromagnetic effect which have been one of the primary geophysical methods used in hydro-geological investigations because of its ability to distinguish between formations of different resistivities. Transient Electromagnetic Method (TEM) are particularly well suited to delineate layered structures of interest in geologic as well as groundwater exploration and for assisting in mapping boundaries between freshwater and saltwater in coastal aquifers because of its ability to detect good conductors. In the Wadi Thuwal area of Saudi Arabia a total of 99 TEM sounding sites were chosen to provide a uniform distribution along the study area where land was accessible. These TEM soundings were conducted during October-November 2008; Al-Garni and El-Kaliouby [21] conducted a geophysical reconnaissance study to determine whether time-domain electromagnetic sounding could be used to delineate the freshwater/saline water transition zone in Wadi Thuwal. This application of TEM sounding also was a test to indicate whether high-quality data could be obtained from the required depths and whether relatively low-resistivity clayey surface layer that is washed during flooding would adversely affect investigators ability to identify deeper layers from TEM measurements. From the results Al-Garni and ElKaliouby [21] characterized Wadi Thuwal by a sharp change in resistivity where the eastern, western, and southern parts of the study area showed lower resistivity than the middle part of 
the Wadi. The lower resistivity shallow regions correspond to saline water or clays while the higher resistivity regions correspond to freshwater which usually accumulates in pockets or in the surface shallow layer due to rain and seasonal flood water Al-Garni and El-Kaliouby [21] .

Sipio and Zezza [22] conducted a case study considering each and every problem that was faced by the coastal areas. They discussed that along with the deterioration of the fresh water reserves due to saline water intrusion, the historic monuments are also been effected mostly by the sea flooding, sea-level rise and frequent storm events. The study was conducted in the City of Venice, Italy. Their study mainly focused on determining the shallow ground water circulation, that presents a relationship between the sea water in the subsoil and salt decay process that effects the civil constructions and monuments. In their study to confirm the existence of the salt water intrusion, electrical conductivity logs, temperature and $\mathrm{p}^{\mathrm{h}}$ and water table values have been collected in several piezometers. Sipio and Zezza [22] confirmed the presence of sea water intrusion in the aquifers by the hydro-chemical characteristics. They also added that the subsoil is directly connected to the lagoons due to high hydraulic conductivity. Not only the fresh water aquifers but also the monuments are affected by the salt water intrusion. Therefore three studies have been conducted within Venice: the Dogana da Mar, the Torre Alberaria (Arsenale) and the Loggetta del Sansovino. These monuments allow a great comparison amongst them of decay patterns affecting the different building materials located in the supratidal area. These monuments have always been a subject of great research and this is the reason why these monuments have been studied in various journals. Sipio and Zezza [22] finally concluded by saying that the city of Venice is a live example of how monuments and civil constructions get affected by the salt water intrusions. The geological configuration of the city subsoil reveals a direct contact between building foundations and shallow aquifers affected by seawater intrusion. They also concluded by saying that if in the future, climate changes become responsible for sea-level rise, Venice and all coastal centers will suffer further deterioration effects.

Ayolabi et al. [23] have studied the saline water intrusion in the coastal aquifer with geophysical and geochemical techniques. The site selected for the study was university of Lagos is surrounded by water bodies such as creek and lagoon. In their study they investigated that weather the adjacent lagoon intruded the coastal aquifer or not. To study the extent of saline water intrusion within university and to evaluate the vulnerability of aquifer. Ayolabi et al. [23] adopted the methodologies which include the combination of geophysical survey and physiochemical measurements. Ayolabi et al. [23] carried out Electrical resistivity tomography (ERT) survey and collected water sample from twenty one boreholes and two lagoons and measured for electric conductivity (EC), total dissolved solids (TDS), $\mathrm{pH}$, etc. They carried out 15 electrical resistivity tomography test on the space ranging from 135 to $664 \mathrm{~m}$ laterally and 45 to $226 \mathrm{~m}$, and founded that the $\mathrm{pH}$ of the water sample is 4.21 to 7.08 which is acidic in nature making $70 \%$ of the sample acidic which was not suitable for consumption according to
USEPA (United State Environmental Protection Standards) and TDS (total dissolved solid) was less than $1 \mathrm{~g} / 1$. Ayolabi et al. [23]concluded the study by stating that the aquifer is intruded by saline water and five major source of pollution is put forwarded by him i.e. pollution from nearby lagoons, creeks, adjoining canal, waste water drainage within the Lagos university and lastly pollution from polluted stream which flow through university and join the lagoon.

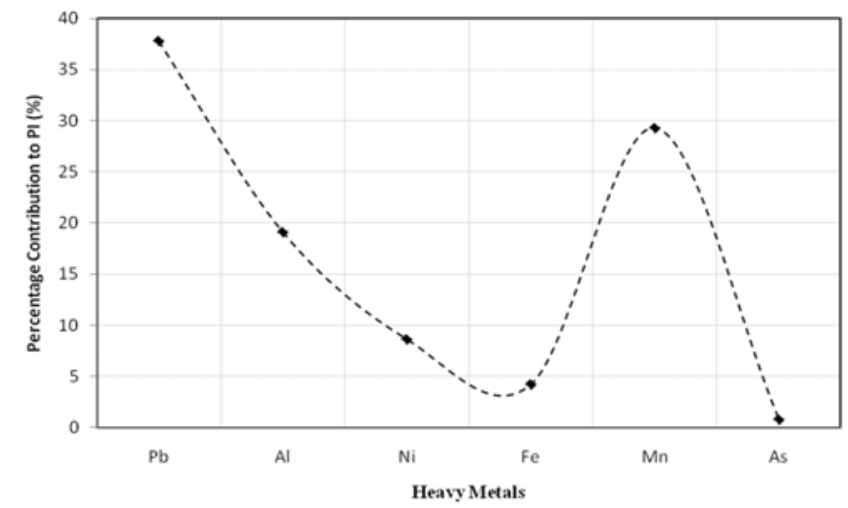

Fig. 2 percentage contributed by significant heavy metals to pollution index (modified after Ayolabi et al. [23]).

Kumar et al. [24] conducted their study in the Nagapattinam area of Southern India. Topographically the area is flat, except beach ridges tending towards the Bay of Bengal. They found that the elevation of the Uppanar river basin (URB) varied from 0 to $14.33 \mathrm{~m}$ above mean sea level (amsl) and in low areas was below $3 \mathrm{~m}$ amsl. Kumar et al. [24] mentioned that the coastal area was mainly subjected to increasing and inconsistent demand of natural resources. they also added that the main phenomenon's that effect the coastal areas worldwide are the coastal erosion, flooding due to river floods, tidal waves or sea level rising contaminates the aquifers (e.g. salt wedge intrusion of seawater). Kumar et al. [24] also mentioned that the extent of saline water intrusion in any coastal area is influenced by the nature of geological formations, hydraulic gradient, rate of withdrawal of groundwater and its recharge. Kumar et al. [24] carried out some ERT and GPR profiles to aim and characterize the groundwater conditions from the inland to the coast. The ERT and GPR profiles were compiled, and a vivid description has been done to distinctive the groundwater in the study area. This included study in the Uppanar river basin and Cauvery river basin. Study was done to demarcate the saline water intrusions from coast to inland.

Kayode et al. [25] stated that salt water intrusion problems were mainly faced by the inhabitants of the coastal areas all over the world. In their paper Kayode et al. [25] brought the fore techniques for proper management of saline water intrusion in coastal region because of the hardship its negligence bring upon the public that rely on it for livelihood. The main factor that was affecting was the quality of water is the saline water intrusion. They pointed out and listed some of the causes of salt water intrusion; among them is the excess groundwater pumping from coastal aquifers than the rate of recharge. Secondly, it has been identified that saline water 
intrusion can also result from the density difference between the more dense saline water in the sea and the less dense fresh water in the aquifer. They understood that saline water intrusion the coastal areas in generally caused by two mechanisms (1) Lateral encroachment from the ocean due to excessive water withdrawals from coastal aquifers and (2) Upward movement from deeper saline zones due to upcoming near coastal discharge or pumping well. They mentioned that in order to manage and control saltwater intrusion, it is necessary to have certain fundamental information on the present state of the groundwater such as the groundwater tables, piezometric levels, salinity distribution and terms of exploitation, i.e. location and rates of abstraction.

Suneetha and Gupta [26] conducted their study in the Sindhudurg district, western Maharashtra, where mostly the gravel and sand aquifers are dominant. They observed that in overburden, aquifers are mostly composed of clayey soil. More specifically the study was done in parts of MalvanVijaydurg-Kankavli, Konkan region. The data was taken out from the Schlumberger electrode configuration at 86 sites using IGIS made SSR-MP-AT instrument, with the current electrode spread of $200 \mathrm{~m}$. The sounding curves were produced from the log-log curve which suggested that the study area has 3-5 layers of structure. The primary parameters were found out by the resistivity and thickness values. Suneetha and Gupta [26] used these primary parameters to establish the secondary geoelectric indicators like transverse resistance (T), longitudinal conductance (S) and coefficient of anisotropy $(\lambda)$. These indicators helped them to interpret the subsurface litho logical and structural characteristics with reduced uncertainty. After the completion of the test and analysis Suneetha and Gupta [26] observed the longitudinal conductance $(\mathrm{S})$ value ranges between 0.0001 to $3.78 \Omega-1$. This value helped to differentiate changes in the total thickness of low resistivity materials. The results of Suneetha and Gupta [26] clearly showed that Dar-Zarrouk parameters provide a practical elucidation in demarcating the saline and fresh water aquifers, particularly when the resistivity data interpretation encounters constraints due to intermixing of saline water aquifers, fresh water aquifers etc. they also added that delineating of potential aquifer zones is often a tedious task as Groundwater typically occurs in discrete aquifers in geologically intricate region. Suneetha and Gupta [26] finally concluded that the Excessive groundwater exploration may seriously affect the groundwater quality through the phenomenon of saline up coning. Therefore they suggested that it was important to maintain a proper balance between the saline water and fresh water bodies in the coastal regions of Konkon region.

Alfaifi et al. [27] studied the extend of saline water intrusion as well as the quality of groundwater decrease by saline intrusion in the Abdarb regions of southwestern Saudi Arabia. The paper consisted of geochemical methods which involved Piper and extended Durov plots to show the extent of groundwater facies in the region. The geophysical method involves seismic refraction (SR), seismic refraction tomography (SRT), vertical electrical soundings (VES) and electrical resistivity tomography (ERT). The number of surveys in geophysical methods are two seismic refraction
(SR) and seismic refraction tomography (SRT), three electrical resistivity tomography (ERT), nine vertical electrical soundings (VES) are carried out. Alfaifi et al. [27] found that in the Piper plots the water is mainly $\mathrm{SO}_{4}-\mathrm{Cl}$ type of arionic facies and in Durov plot water contains base ion exchange, linear mixing and water intrusion. He founded the result from vertical electrical sounding and electrical resistivity tomography that the saline water intrusion is in the intruded zone is increasing towards the sea. They founded four geographical resistivity layers which range from 22.5 to 280 $\Omega \mathrm{m}$. The third layer is a low resistivity zone, with resistivity of 0.3 to $19.5 \Omega \mathrm{m}$. They said this is the main zone which is affected by saline water intrusion and suggested to drill new bore wells in the region and control the rate of amount of pumping to minimize the effect of saltwater intrusion in coastal zone.

\section{Design Recommendations}

Elhamid and Javadi [28] stated that the intrusion of saline water in groundwater is considered a special category of pollution, making groundwater unsuitable for human, industry and irrigation uses. SWI reduces the freshwater storage in coastal aquifers and in extreme cases can result in abandonment of freshwater supply wells if concentration of dissolved salts exceeds drinking water standard. That was reason why they suggested a new method which is considered to be the most cost- effective method. This methodology ADR (Abstraction, Desalination and Recharge) includes; abstraction of saline water and recharge to the aquifer after desalination. A coupled transient density-dependent finite element model is developed for simulation of fluid flow and solute transport and used to simulate seawater intrusion. A number of researchers have applied simulation models for the control of seawater intrusion seeking for optimal management strategy by trial-and-error. This has proved to be time consuming and laborious. In addition, the results obtained may not be optimal. The main reason for this is the inability of this approach to consider important physical and operational constraints. To accommodate these constraints, coupling of the simulation model with a management model is the generally adopted procedure to solve the optimization problem because of its effectiveness in finding the global optimum solution. 


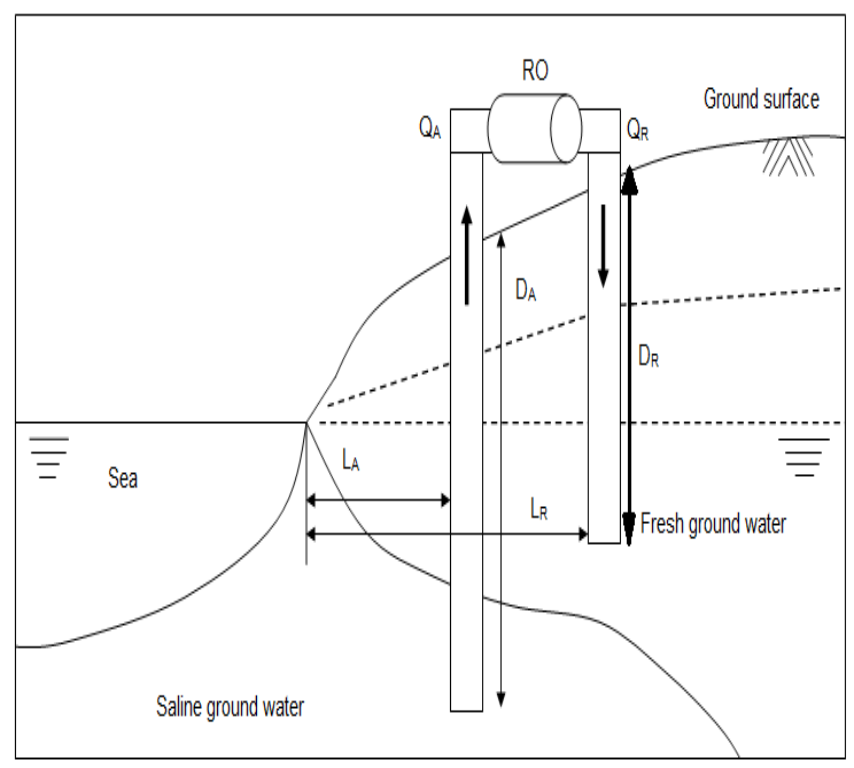

Fig 3 ADR methodology (modified after Elhamid and Javadi [28])

The developed model of the simulation- optimization is applied to the Henry's problem to properly study the SWI to study exactly the effect of ADR method in controlling of the saltwater intrusion and also compare the results with other scenarios. The results are presented and a comparison is presented between the three scenarios in terms of total cost, total amount of water abstracted or recharged and total salt concentration remained in the aquifer. The results in terms of the optimal depths, locations and abstraction rates for the wells, together with the corresponding total cost are summarized. A comparison between the combined ADR system and the individual abstraction or recharge system is made in terms of total cost and total salt concentration in the aquifer and abstraction/recharge rates are presented in Fig. Using ADR in management model 3 the total cost was found to be USD 0.13 million per year. A comparison between the combined ADR system and the individual abstraction or recharge system is made in terms of total cost and total salt concentration in the aquifer and abstraction/recharge rates and the results are shown in Fig. 4

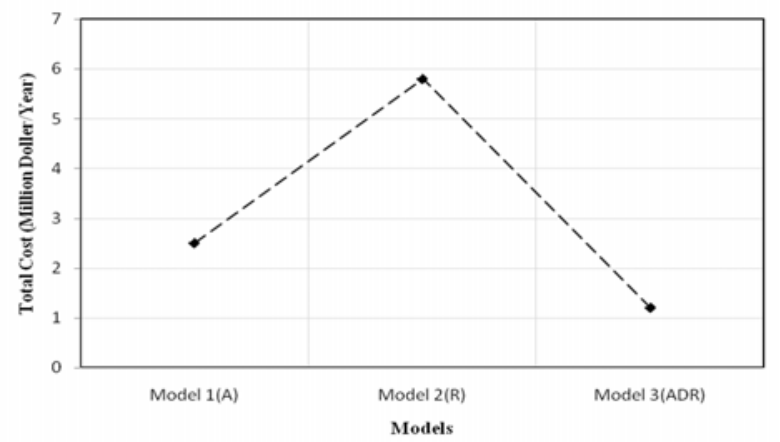

(a)

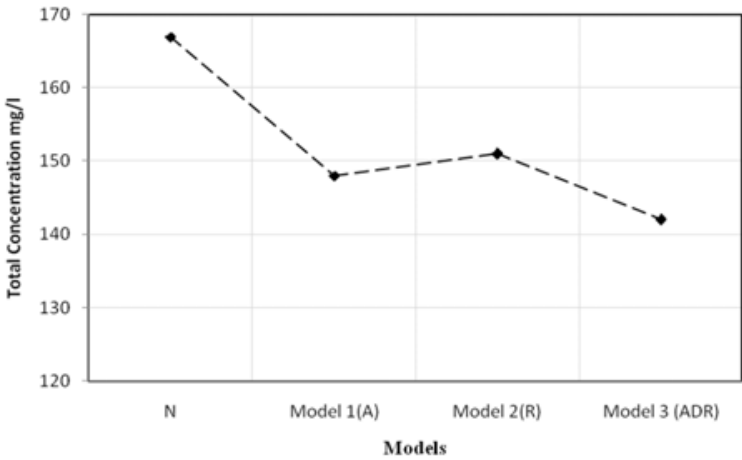

(b)

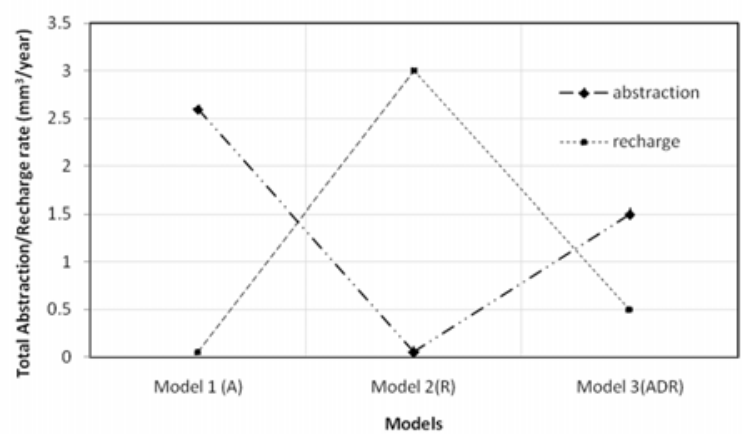

(c)

Fig 4 comparisons of different models with (a) total cost, (b) total saline concentration, and (c) total abstraction and recharge rate. (Modified after Elhamid and Javadi [28])

Basack et al. (29) stated that adoption of scientific methods of ground water management is very important in coastal regions because of the complexity of hydro geological setup. Basack et al. (29) developed a convenient and easily implementable analytical model for coastal groundwater management aimed at the control of saltwater intrusion. The technique includes withdrawal of coastal freshwater by means of Qanat-well structures associated with artificial recharge through rainwater harvesting aided by percolation ponds and recharge wells. The proposed methodology is suitable specifically for not highly urbanized coastal areas with significant annual precipitation, good hydraulic conductivity of the aquifer and a low depth of fresh groundwater.

Augustjin et al. [30] study the salt water intrusion in the Mark-Vliet River system which is situated west of province Noord Brabantin, NetherlandsAugustjin et al. [30] the catchment area of mark-vliet River cover the area of 140,000 ha. In his study, Augustjin et al. [30] used SOBEK version 2.11c for the modelling approach of Mark-Vliet River system and following modules were also used such as (1) rainfallrunoff module which calculates the runoff and drainage by using water balance for different elements, (2) to calculate the flow velocities and water depth (3) The third module he used is water quality module which is used to measure transport of 
substance based on the advection-dispersion equation and reactive process.(4) To simulate strategies and dynamic processes real time control modules is used in this study to decrease the concentration of salt continuous additional discharge of $15 \mathrm{~m}^{3} / \mathrm{sec}$ to flushed the mark vliet river system which results in reduction of chloride concentration to desired level in first intake i.e. Dintel. However the chloride concentration is more than $300 \mathrm{mg} / \mathrm{L}$ in the vliet.

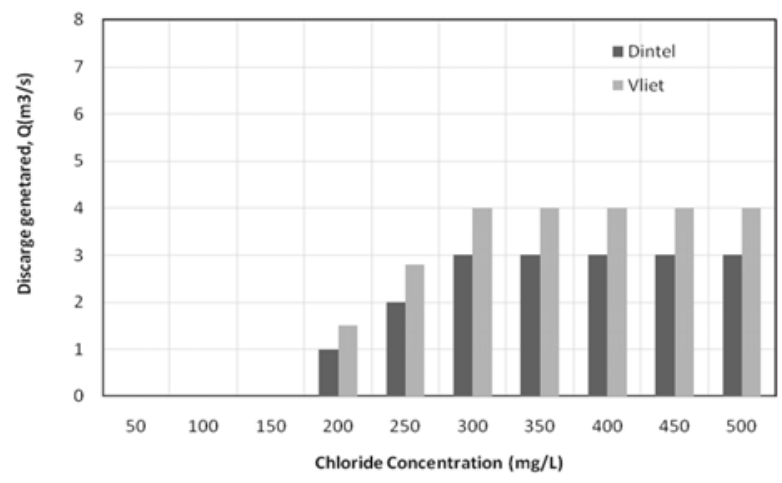

Fig. 5 discharge generated by opening of the drainage sluices in the Dintel and Vliet as a function of the chloride concentration $200 \mathrm{~m}$ downstream of the polder intake (modified after Augustjin et al. [30]).

Cai et al. [31] knew that in the coastal and inland aquifers all over the world salt water intrusion is a widespread intrusion problem. The study was done in the area of Berlin, Germany where salt water intrusion is a widespread problem. They described that salinity is a special case of contamination where it makes the ground water unsuitable for human, irrigation and industrial uses by reducing the fresh water reserves. They also mentioned that in coastal aquifers many studies have already been done to control the salinity in water which includes the rearrangement of pumping pattern, use of artificial recharge, some effective construction of subsurface barriers, etc. But all these methods had their demerits except the first method that includes the rearrangement of pumping patterns. According to Cai et al. [31] this method was found to be the most effective and economic along with the analytical and numerical model. They also observed that in most of the abstraction wells there is a enormous increase of salinity at a depth of $50 \mathrm{~m}$ below the ground surface in the inland aquifers of Beelitzh of waterworks (BEEWW) in southwestern Berlin, Germany, and this aquifers provided almost $15 \%$ of the drinking water to the area. Therefore they assumed that salt water intrusion would generate at a deeper saline ground water. The geological conditions in the Northern German were also supporting this assumption of Cai et al. [31]. They demonstrated their study with a conceptual model and a numerical model. Cai et al. [31] concluded by saying that their study was special because it's the first time that a theoretical model was used to provide the recommendations to control the saline water intrusions in the inland aquifer for the purpose of drinking water.

\section{CRITICAL REVIEW}

From the above study we understood that saline water intrusion is nothing but the entry of saline water/salt water into the fresh water aquifers. Going through the different journals from different writers including contents of almost every corners of the earth, we understood that saline water intrusion problem is a common problem in the coastal aquifers. We understood and filtered some major problems that cause the salt water intrusion. First is the excess pumping from the ground water mainly in the coastal areas. Secondly, in most of the cases it is found that salt water intrusion is mainly occurred due to density differences between the more dense saline water in the sea and the less dense fresh water in the aquifer. It occurs where groundwater is being pumped from aquifers that are in hydraulic connection with the sea, the induced gradients may cause the migration of salt water from the sea towards a well, making the freshwater well unusable. There are numerous numbers of factors affecting the salt water intrusion but the renowned columnists have listed out some major problems such as,

1. Tidal fluctuation

2. Long-term climate and sea level changes

3. Fractures in coastal rock formations

4. Seasonal changes in evaporation

5. Recharge rates

Effects of climate change and sea level rise are some of the factors to consider when choosing control techniques for saltwater intrusion. Climate change has resulted in increase in the sea level because rising temperature causes expansion of seawater and melting of glaciers/ice caps. This change in climatic condition also results in reduction in the atmospheric pressure which as a result leads to increase in water level in seas.

From the study of above journals also brought us to listing some of the techniques or measures that can be considered The new technique for controlling saltwater intrusion is the Abstraction, Desalination and Recharge (ADR) which consists of three (3) steps; abstraction of brackish water from the saltwater, desalination of the abstracted brackish water using treatment process, and recharge of the treated water into the aquifer, Elhamid and Javadi [28]. Abstraction-Recharge process helps to move freshwater/saltwater interface towards the sea and is considered as an efficient method to control saltwater intrusion.

Increase aquifer recharge using controlled river flood is another technique, in that, some adjacent river areas that gets flooded during high volume rainfall events can slowly infiltrate after the storm. Back movement of seawater could be seen after using this method within one year. The movement may be insignificant, but in collaboration with other methods, it is possible to eradicate saltwater intrusion.

Another cheap control is to reduce and/or rearrange the pattern of boreholes abstraction of groundwater. This approach implies that in rainy season, boreholes near the sea are used to provide most of the supply while inland boreholes are rested because large quantity of freshwater flow to the sea during this season. This situation is reversed in the summer when the flow of freshwater to the sea is much reduced. 
More extensive studies are required for prediction, prevention and to control of salt water intrusion due to rise in sea level. Coastal environment including the rise in sea level effects the aquifer by which it generally occurs due to climate change. Human activities alter the amount of recharge to the aquifer, which ultimately leads to the salt water intrusion. To understand the impact of human activities on water resources proper evaluation of hydraulic conditions such as aquifer pumping and injection of wastewater needs to be done.

One bigger problem is the excessive extraction of ground water from coastal aquifers which also results in salt water intrusion, inducing significant alteration in geological parameters such as hydraulic conductivity, dry density, optimum moisture content, plastic limit and liquid limit of the aquifer soil. These characteristics are very important factors and can be analyzed to measure saline water intrusion.

Recycling of water in industrial processes, after appropriate treatment have been administered to it. Reduction of the rates of abstraction, in order not to exceed the sustainable yield. Waste water to be reused for application such as cooling, irrigation and injection into the subsurface to maintain barrier against saltwater intrusion, O.T. Kayode et al. [25]. Some relevant studies about the Water can be found in the articles [32], [33] and [34].

\section{ACKNOWLEDGMENT}

The authors thankfully acknowledge the in-kind support received from the Department of Civil Engineering, Scholar's Institute of Technology and Management, Assam, India, during analysis and interpretations of this work.

\section{REFERENCES}

[1] M. L .Calvache, and A.P. Bosch, "Effects of geology and human activity on the dynamics of salt-water intrusion in three coastal aquifers in southern Spain" Environmental Geology, 1996, pp. 215-223.

[2] M. G. Khublaryan, A. P. Frolov, and I. O. Yushmanov, "Seawater Intrusion into Coastal Aquifers" Water Resource, vol. 35, no. 3, 2008 , 288-301.

[3] A. R. Kacimov, M. M. Sherif, J. S. Perret and A. A. Mushikhi, "Control of sea-water intrusion by salt-water pumping: Coast of Oman" Hydrogeology Journal, vol. 17, 2009, pp. 541-558.

[4] L.S. Naidu, G. V. V. S. Rao, T. G. Rao, J. Mahesh, G. Padalu, V. S. Sarma, P. R. Prasad, S. M. Rao and R. B. M. Rao, "An integrated approach to investigate saline water intrusion and to identify the salinity sources in the Central Godavari delta, Andhra Pradesh, India" Arabic journal Geoscience, vol. 6, 2013, pp. 3709-3724.

[5] A. Javadi, M. Hussain, M. Sherif, and R. Farmani, "Multi-objective Optimization of Different Management Scenarios to Control Seawater Intrusion in Coastal Aquifers" Water Resource Management, vol. 29, 2015, pp. 1843-1857.

[6] N. Momejian, N. M. Abou, I. Alameddine, and M. El-Fadel, "Can groundwater vulnerability models assess seawater intrusion?" Environmental Impact Assessment Review, 75, 2019, pp. 13-26.

[7] S. Stein, Y. Yechieli, E. Shalev, R. Kasher, and O. Sivan, "The effect of pumping saline groundwater for desalination on the freshe saline water interface dynamics" Water Research, vol. 156, 2019, pp. 46-57.

[8] B. J. Kefford, "The effect of saline water disposal: implications for monitoring program and management" Environmental Monitoring and Assessment, vol. 63, 1999, pp. 313-327.

[9] M. M. Rahman, M. Q .Hassan, M. S. Islam and S. Z. K. M. Shamsad, "Environmental impact assessment on water quality deterioration caused by the decreased Ganges outflow and saline water intrusion in southwestern Bangladesh" Environmental Geology, 2000, pp. 31-40.

[10] K. Choudhury, D. K. Saha and P. Chakraborty, "Geophysical study for saline water intrusion in a coastal alluvial terrain" Journal of Applied Geophysics, 46, 2001, pp. 189-200.

[11] L. Vives, M. Varni and E. Usunoff, "Behavior of the fresh- and salinewater phases in an urban area in Western Buenos Aires Province, Argentina" Hydrogeological Journal, vol. 13, 2005, pp. 426-435.

[12] D. A. Carlson, T.P.V. Biersel and L. R. Milner, "Storm-Damaged SalineContaminated Boreholes as a Means of Aquifer Contamination" Ground Water, vol. 46, no. 1, 2006, pp. 69-79.

[13] H. A. Loaiciga, T. J. Pingeland and E. S. Garcia, "Sea water intrusion by sea level rise: Scenarios for 21 st century" Ground Water, vol. 50, no. 1, 2011, pp. 37-47.

[14] C. Singaraja, S. Chidambaram, P. Anandhan, M.V. Prasanna, C. Thivya and R. Thilagavathi, "A study on the status of saltwater intrusion in the coastal hard rock aquifer of South India" Environmental Dev Sustain, 2015, pp. 443-475.

[15] D. Han, V. E. A. Post and X. Song, "Groundwater salination processes and reversibility of seawater intrusion in coastal carbonate aquifers" Journal of Hydrology, 531, 2015, pp. 1067-1080.

[16] M.T. Ngo, J, M. Lee, J. A. Lee and N. C. Woo, "The sustainability risk of Ho Chi Minh City, Vietnam, due to saltwater intrusion" Geosciences Journal, vol. 19 , no. 3, 2015,547-560.

[17] S. Liu, Z. Tang, M. Gao and G. Hou, "Evolutionary process of salinewater intrusion in Holocene and Late Pleistocene groundwater in southern Laizhou Bay" Science of the Total Environment, 607-608, 2017, pp. 586-599.

[18] Y. Xu, W. Zhang, Y. Zhu and J. Zheng,) "Analytical solution for salt intrusion in multiple-freshwater source estuaries: application to Humen Estuary" Environmental Earth Science, 2017, pp. 1-11.

[19] H. Qiu, , L. Dang-yan, L. Guan-qun and N. Pi-hai, "Saline water intrusion and its influence in the Laizhou Area" Chinese journal on Oceanology and Limnology, vol.15 no. 4, 1997, 342-349.

[20] X. Yuqun, , W. Jichun, , X. Chunhong and Z. Yongxiang,) "Sea water intrusion and salt water intrusion in the coastal area of Laizhou Bay" Chinese Science Bulletin, vol. 43, no. 12, 1998, 983-992.

[21] M.A. Al-Garni and H. M. El-Kaliouby, "Delineation of saline groundwater and sea water intrusion zones using transient electromagnetic (TEM) method, Wadi Thuwal area, Saudi Arabia" Arabic Journal of Geoscience, 2009, pp. 655-668.

[22] E. D. Sipio and F. Zezza, "Present and future challenges of urban systems affected by seawater and its intrusion: the case of Venice, Italy" Hydrogeology Journal, vol. 19, 2011, pp. 1387-1401.

[23] E. A. Ayolabi, A. F. Folorounso, A. M. Odukoya and A. Adeniran, "Mapping saline water intrusion into the coastal aquifer with geophysical and geochemical technique: the University of lagos campus case (Nigeria)" SpringerPlus, 2013, pp. 1-14.

[24] V. S. Kumar, R. Dhakate, B. Amarender and S. Sankaran, "Application of ERT and GPR for demarcating the saline water intrusion in coastal aquifers of Southern India" Environmental Earth Science, vol. 393, no. 75, 2016, pp. 1-17.

[25] O.T. Kayode, A. M. Odukoya and T. A. Adagunodo, "Saline Water Intrusion: Its Management and Control" Journal of Informatics and Mathematical Sciences, vol. 9, no. 2, 2017, pp. 493-499.

[26] N. Suneetha, and G. Gupta, "Evaluation of groundwater potential and saline water intrusion using secondary geophysical parameters: A case study from western Maharashtra, India” E3S Web of Conferences, 2018, pp. 1-6.

[27] H. Alfaifi, A. Kahal, A. Albassam, E. Ibrahim, K. Abdelrahman, F. Zaidi and S. Alhumidan, "Integrated geophysical and hydrochemical investigations for seawater intrusion: a case study in southwestern Saudi Arabia" Arabian Journal of Geosciences, 2019, pp. 1-14.

[28] H. F. A. Elhamid, and A. A. Javadi, "A Cost-Effective Method to Control Seawater Intrusion in Coastal Aquifers" Water Resource Management. 25, 2011, pp. 2755-2780.

[29] S. Basack, A. K. Bhattacharya and P. Maity, "A coastal ground water management model with Indian case study", Proceedings of the Institution of Civil Engineers: Water Management: Water Management, 2014, 126-140.

[30] D.C.M. Augustijn, M.V.D. Berg, E.D. Bruine and H. Korving, "Dynamic Control of Salt Intrusion in the Mark-Vliet River System, The Netherlands" Water Resource Management, 2011, pp. 1005-1020. 
[31] J. Cai, T. Taute and M. Schneider, "Recommendations of Controlling Saltwater Intrusion in an Inland Aquifer for Drinking-Water Supply at a Certain Waterworks Site in Berlin (Germany)" Water Resour Manage, vol. 29, 2015, pp. 2221-2232

[32] Ilir Morina, Agim Neziri, Andina Vllahiu, Naser Bajraktari, Valmir Zogaj, Merita Mehmeti, The Analysis of the Building Structure Situation, Accumulation and Distribucion of the "Ujemani" Watersheds and its Impact on the Effectiveness of Catchments, WSEAS Transactions on Environment and Development, Volume 13, 2017, pp. 242-251

[33] Luis Hebert Palma Pulido, Jocelyn Portela Arévalo, Ruben Darío Lerma Piedrahita, Carlos Hernán Méndez Díaz, Diego Bonilla Ocampo, Descriptive Analysis of the Water Balance in Swimmers of the Club Orcas Tuluá, WSEAS Transactions on Environment and Development, Volume 14, 2018, pp. 619-629

[34] Maria Macchiaroli, Vincenzo Pellecchia, Chiara D'Alpaos, Urban Water Management in Italy: An Innovative Model for the Selection of Water Service Infrastructures, WSEAS Transactions on Environment and Development, Volume 15, 2019, pp. 463-477

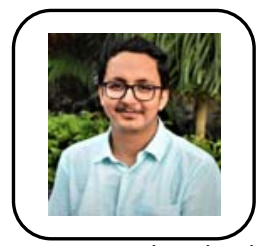

Ghritartha Goswami, BE, M.Tech. is a Professional civil and water resources engineer and currently an Assistant Professor at Scholar's Institute of Technology and Management, Guwahti, Assam, India. He graduated in civil engineering in the year of 2017 from Nagpur University, Maharashtra, India and post-graduated in water resources engineering in the year of 2019 from Assam Kaziranga University, Jorhat, Assam, India. He has participated in various renowned conferences and presented papers.

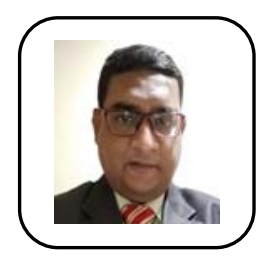

Sudip Basack, PhD, FIE, M.ASCE is a civil engineering professional with vast academic experience at responsible senior positions in India and abroad. He published more than 100 technical papers in reputed journals and conferences and is recipient of several research awards at national and international levels. He is an active reviewer of numerous top-class international journals. He has supervised more than 10 research students at postgraduate (Masters and $\mathrm{PhD}$ ) levels and executed sponsored research projects in different Universities. He has undertaken several academic visits in many countries including USA, UK, Germany, Australia, New Zealand, Singapore, China, etc.

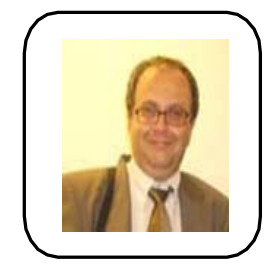

Nikos Mastorakis studied Medicine in the University of Athens 1982-1984 and 1988-1992. $\mathrm{He}$ received the Diploma (B.Sc.+M.Sc) of Electrical Engineering from the National Technical University of Athens with grade "Excellent" (9.33) in 1988, and the B.Sc. in Mathematics with grade "Excellent" (8.65) from the National and Kapodistrian University of Athens, Department of Mathematics in 1995. In 1992 he received his PhD

in Electrical Engineering and Applied Mathematics with grade "Excellent" (10) from the National Technical University of Athens.

Academic Positions:

a) Professor at National Technical University of Sofia, Bulgaria since 2008,

b) Professor Military Institutes of University Education (ASEI), Hellenic Naval Academy (HNA) since 1996,

c) Visiting Professor, University of Exeter, United Kingdom, 1998-1999,

d) Visiting Professor, National Technical University of Sofia, Bulgaria, 20022003

e) Visiting Professor at the National Technical University of Sofia, Bulgaria, 2007-2008,

f) Honorary Professor at the Technical University of Cluj-Napoca, Romania, since 2008

g) Prize of Excellence and Honorary Professor in the Romanian Academy of Science, Bucharest, 2008,

f) Honorary Professor at the Budapest Tech, Budapest, Hungary since 2009

g) Honorary Professor. Obuda University, Budapest, Hungary since 2011

h) Visiting Professor, University of Salerno, Salerno, Italy, 2014-2015

$\mathrm{He}$ is an active researcher in Systems Theory, Computers, Environment and Mechanics. He is among the Seven Greek researchers among the overproductive ones in the world according the Professor John Ioannides (Stanford University of California Medical School) with many papers and many citations.

https://www.ellines.com/en/good-news/41299-seven-greekresearchers-among-the-over-productive-ones-in-the-world/

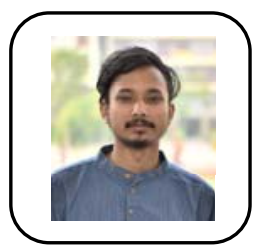

Abhishek Saikia, B.Tech. Final year grdauation student in Department of Civil Engineering, Schoar's Institute of Technology and Managemnt. Guwahati, Assam, India

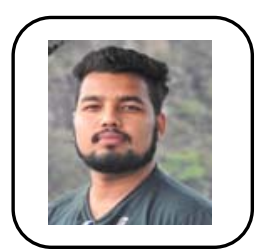

Baby Nilo, B.Tech. Final year grdauation student in Department of Civil Engineering, Schoar's Institute of Technology and Managemnt. Guwahati, Assam, India

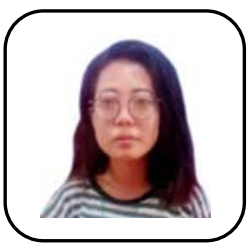

Nasir Ahmed, B.Tech. Final year grdauation student in Department of Civil Engineering, Schoar's Institute of Technology and Managemnt. Guwahati, Assam, India 